\title{
Reconstrução com retalho miocutâneo anterior da coxa após hemipelvectomia por carcinoma de células escamosas de região glútea: relato de caso
}

Anterior thigh myocutaneous flap for reconstruction after external hemipelvectomy performed to treat a buttock squamous cell carcinoma: case report

Danton Spohr Corrêa, Benedito Mauro Rossi, Fábio de Oliveira Ferreira, Wilson Toshihiko Nakagawa,

Gustavo Cardoso Guimarães e Ademar Lopes

Resumo

$\mathrm{H}$ emipelvectomia utilizando retalho miocutâneo anterior é indicada para tumores extensos da região glútea e parte posterior proximal da coxa. Um paciente do sexo masculino com 49 anos apresentou-se para tratamento de tumor ulcerado einfectado com crescimento progressivo há 3 anos em região glútea esquerda, originado de uma área de ulceração e cicatrização crônicas provocadas pela aplicação de múltiplas injeções de drogas ilícitas no local. 0 tumor infiltrava a pele, tecido celular subcutâneo e musculatura glútea, estando fixo ao osso ilíaco, articulação coxo-femural e trocanter maior. A tomografia computadorizada da pelve confirmou os achados do exame físico. A biópsia aberta foi realizada e revelou um carcinoma de células escamosas. H emipelvectomia externa foi a opção escolhida para o tratamento. Um grande defeito foi criado após ressecção da extremidade inferior, hemipélvis e glúteo. Um retalho miocutâneo anterior do músculo quadríceps femural, adutores, sartório, pectíneo e grácil com pele e tecido celular subcutâneo sobrejacentes foi realizado. $0 \mathrm{~s}$ vasos femurais foram utilizados para manter o retalho viável. A recuperação pós-operatória aconteceu sem intercorrências e o retal ho permaneceu totalmente viável. Alguns aspectos da técnica são apresentados.

Palavras-chave: hemipelvectomia; recontrução; retalhos cirúrgicos; coxa. 


\begin{abstract}
$\mathrm{H}$ emipelvectomy utilizing an anterior myocutaneous flap is indicted for extensive tumors of the buttock and posterior proximal portion of the thigh. A 49-year-old man came to the clinic with a tumor that had been progressively growing over three years. It was at the left buttock, and originated from an area of a previous scar and chronic ulceration. The tumor was infected and ulcerated, infiltrating to skin, subcutaneous fat, and gluteal musculature, being fixed to the iliac bone, hip joint and great trocanter. A CT-scan of the area showed infiltration of the structures above. An open bi opsy was done and revealed a squamous cell carcinoma. External hemipelvectomy was the treatment option. A large defect was created after resection of the lower extremity, hemipelvis and buttock. An anterior myocutaneous flap of the quadriceps femoris, adductors, sartorius, pectineum and gracilis muscles with overlying subcutaneus fat and skin was done. The femoral vessels were used to mantain the flap viable. The post-operative course was uneventful and the flap remained fully viable. Some aspects of the technique are presented.
\end{abstract}

Key words: hemipelvectomy; reconstruction; surgical flap; thigh.

\section{INTRODUÇÃO}

U m dos problemas encontrados após realização de hemipelvectomia externa para tratamento detumoresinfiltrando musculatura glútea é a escolha do retalho apropriado para reparar o grande defeito criado. Em uma hemipelvectomia padrão, o retalho miocutâneo de musculatura glútea é o mais utilizado. Para extensos tumores glúteos ou da região proximal posterior da coxa que necessitam hemipelvectomia para tratamento, o retalho miocutâneo anterior da coxa mantido pelos vasos femurais é sem dúvida a opção mais apropriada e segura. N o presente caso, relatamos o uso deste retalho para o reparo de extensa área cruenta criada após hemipelvectomia por carcinoma de células escamosas da região glútea esquerda. Alguns aspectos da técnica serão discutidos.

\section{RELATO DO CASO}

Paciente do sexo masculino, com 49 anos, apresentou-se para tratamento em março de 2001 com extensa tumoração ulcerada e infectada na região glútea esquerda, medindo $17 \times 16 \mathrm{~cm}$, fixa ao osso iíaco, articulação coxo-femural e grande trocanter (Figura 1). 0 tumor originou-se três anos antes, em uma área de cicatrização e ulceração crônicas provocadas pela aplicação de múltiplas injeções intramusculares de drogas ilícitas no local entre 1978 e 1981. Foi realizada biópsia aberta e o diagnóstico de carcinoma de células escamosas bem diferenciado infiltrativo foi obtido. A tomografia computadorizada de região pévica confirmou os achados do exame físico (Figura 2). A radiografia de tórax e a tomografia computadorizada de abdome superior foram normais. D evido à localização e extensão da lesão, uma hemipelvectomia externa tipo IV foi realizada. A reconstrução foi feita com 0 retalho miocutâneo anterior da coxa (Figura 3). 0 paciente recebeu três unidades de concentrado de hemácias durante a operação. A recuperação pós-operatória aconteceu sem intercorrências, a não ser pela ocorrência de dor fantasma. 0 paciente recebeu alta no $7^{\circ}$ dia pós-operatório, com integração completa do retalho. 0 exame anátomo-patológico definitivo confirmou 0 achado inicial, assim como a invasão de osso ilíaco. As margens operatórias da peça cirúrgica estavam livres de neoplasia. 
Figura 1. Tumor úlcero-infiltrativo envolvendo a região glútea e face lateral da coxa esquerda.

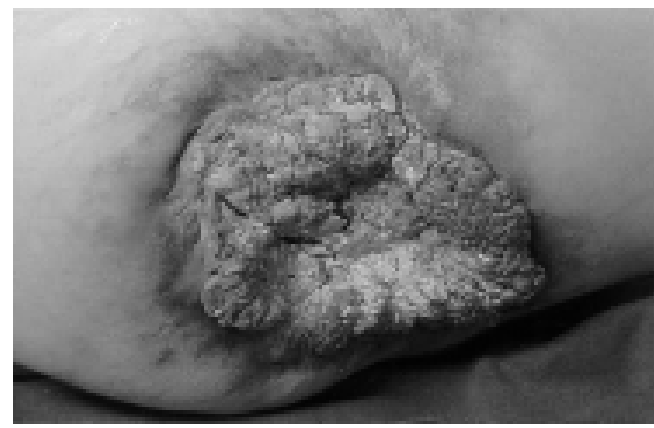

Figura 2. Tomografia computadorizada da pelve mostrando o tumor ulcerando e infiltrando a pele, tecido celular subcutâneo e musculatura glútea, atingindo a região periacetabular.

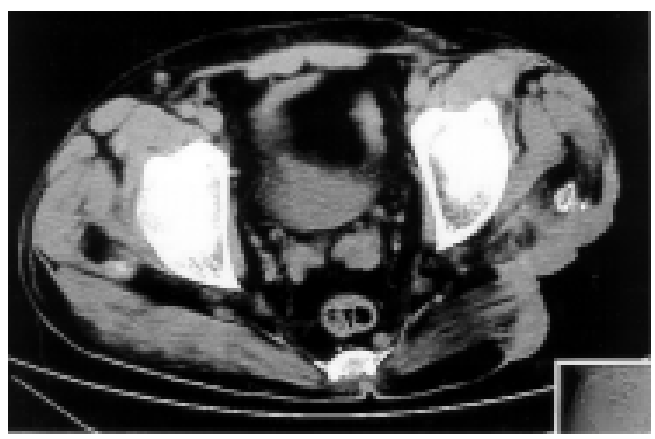

\section{DISCUSSÃO}

Tumores extensos da região pélvica invadindo osso, partes moles, nervos e vasos são difíceis de tratar conservadoramente. $A$ hemipelvectomia externa pode ser a única alternativa para a ressecção de tais tumores com margens adequadas e com um intervalo livre de doença aceitável. ${ }^{1,2} \mathrm{~A}$ hemipelvectomia com retalho miocutâneo anterior da coxa é indicada nos casos onde ossos pélvicos, terço proximal do fêmur, nervo ciático epartesmoles glúteas, como no caso presente, estão envolvidos por tumor. ${ }^{1}$ Para ressecção curativa, o tumor não pode envolver os vasos ilíacos comuns ou externos, que devem ser preservados para manter o fluxo sangüíneo para o retalho. Em anos passados, tumores como o descrito eram considerados irressecáveis, devido à falta de uma opção adequada para a reconstrução.
Figura 3. A- visão lateral do retalho. A incisão é feita desviando do tumor. Bvisão anterior do retalho. A incisão é feita logo acima do joelho. C- retalho levantado após a hemipelvectomia; o quaríceps femural é mostrado. D- resultado final.

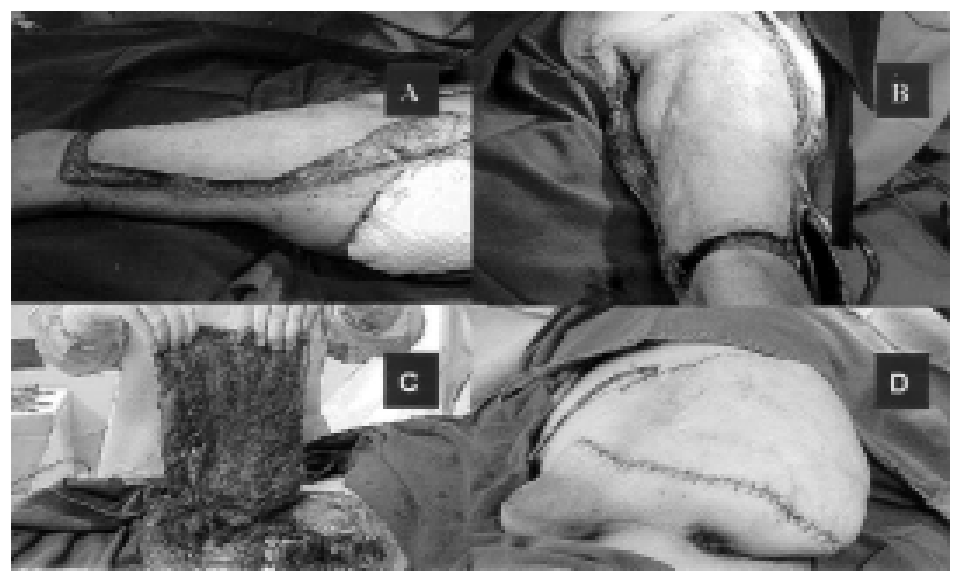

Retal hos de parede abdominal cutâneos ou miocutâneos assim como a rotação de epiplon com enxertia cutânea têm resultados e complicações desapontadores quando comparados ao retalho miocutâneo anterior. Frey et $\mathrm{al}^{3}$ foram os primeiros a descrever 0 retalho miocutâneo anterior em 1976. Lopes et al ${ }^{4}$ padronizaram a técnica em 1981 . Toda a pele, tecido celular subcutâneo e musculatura da parteanterior da coxa compõe a unidade miocutânea do retalho. Os músculos quadríceps femural, adutores, sartório, pectíneo e grácil formam o componente muscular. 0 fluxo sangüíneo para o retalho é mantido através dos vasos femurais, que são seccionados $4 \mathrm{~cm}$ acima do joelho. Os nervos femural e obturador mantêm a inervação motora, evitando a atrofia do retalho. A sensibilidade cutânea é mediada pelos nervos genitofemural e cutâneo femural lateral. As complicações pós-operatórias são raras, sendo a isquemia cutânea incomum. A dor fantasma presente neste caso tem incidência similar a qualquer outro tipo de amputação e foi tratada com sucesso. 0 potencial de reabilitação é satisfatório, sendo possível em pacientes altamente motivados à adaptação de uma prótese sobre o retalho e a deambulação sem 0 auxílio de muletas. ${ }^{1}$ Em conclusão, o retal ho miocutâneo anterior da coxa é uma opção segura para o reparo de grandes defeitos criados após hemipel vectomias para tumores de região glútea e parte proximal posterior da coxa, e mesmo para tumores 
intrapélvicos, desde que não haja Karakousis CP. Various types of hemipelveccomprometimento dos vasos femurais. tomy for soft tissue sarcomas: complications, survival and prognostic factors. Surg O ncol 1995;4(4):217-22.

REFERÊNCIAS BIBLIOGRÁFICAS

1. Sugarbaker PH, Chretien PA. H emipelvectomy for buttock tumors utilizing an anterior myocutaneous flap of quadriceps femoris muscule. Ann Surg 1983;197:106-15.

2. Apffelstaedt JP, Zhang PJ, D riscoll DL,
3. Frey $\mathrm{C}, \mathrm{M}$ atthewsLS, Benjamin $\mathrm{H}$, Fidler WJ. A new technique for hemipelvectomy. Surg Gynecol 0 bstet 1976;143(5):753-6.

4. AzevedoJF, Caríssimo LA, LopesA, G entil FC. Retal ho miocutâneo antero-medial da coxana hemipelvectomia. Acta O ncol Bras1981; 1:325-3. 